\title{
Wesbite e-Commerce Lia Cake (Studi Kasus : Lia Cake di Desa Rumbai Jaya Kecamatan Kempas)
}

\section{Dwi Yuli Prasetyo}

\author{
Program Studi Sistem Informasi, Universitas Islam Indragiri \\ Jln.Provinsi Parit1 Tembilahan - Indragiri Hilir - Riau \\ Email : dwiyuliprasetyo@gmail.com
}

\begin{abstract}
A cottage industry business units on a small scale in a particular industry. These efforts usually uses only one or two of the House as the center of production, administration and marketing at once simultaneously. When viewed from venture capital and the amount of energy absorbed is certainly less than big companies in General. Proven internet technologies is one of the media information that is efficient and effective in the dissemination of information that can be accessed by anyone, anytime and anywhere. So it is with Lia Cake home industry, an industry of households should be able to make information services and promotions to attract the attention of consumers. In addition to accurate information, fast, and easy, information submitted should be packed with interesting. System sales cottage industry of Lia Cake was by way of phone or sms and is not yet online, to promote it only from the mouth to the mouth. Sales system in this way takes a long time in the sales process, then the system is judged less effective and efficient. If you only rely on sales system in a way that the income of this household industry entrepreneurs have not experienced a significant increase. In addition to this household industry feels judged a bit slow. Therefore be designed a system of online sales by using a website with the goal to minimize the time the sales process with the aim of can increase the sales volume of household industry revenues so it can increased and customers may affect booking products without having to come directly to the cottage industry of Lia Cake.
\end{abstract}

Keywords: website, industry, home, internet, staircase

\begin{abstract}
Abstrak
Industri rumah tangga suatu unit usaha dalam skala kecil yang bergerak dalam bidang industri tertentu. Biasanya usaha ini hanya menggunakan satu atau dua rumah sebagai pusat produksi, administrasi dan pemasaran sekaligus secara bersamaan. Bila dilihat dari modal usaha dan jumlah tenaga yang diserap tentu lebih sedikit daripada perusahaan-perusahaan besar pada umumnya. Teknologi internet sudah terbukti merupakan salah satu media informasi yang efektif dan efisien dalam penyebaran informasi yang dapat diakses oleh siapa saja, kapan saja dan dimana saja. Begitu halnya dengan industri rumah tangga Lia Cake, sebuah industri rumah tangga harus dapat membuat layanan informasi dan promosi dengan baik untuk menarik perhatian konsumen. Disamping informasi yang akurat, cepat, dan mudah, informasi yang disampaikan harus dikemas dengan menarik. System penjualan industri rumah tangga Lia Cake adalah dengan cara telpon atau sms dan belum secara online, untuk mempromosikannya hanya dari mulut kemulut. Sistem penjualan dengan cara ini membutuhkan waktu yang lama dalam proses penjualan, maka sistem ini dinilai kurang efektif dan efesien. Jika hanya mengandalkan sistem penjualan dengan cara tersebut maka pendapatan pengusaha industri rumah tangga ini tidak mengalami peningkatan yang signifikan. Selain itu perkembangan industri rumah tangga ini terasa dinilai agak lambat. Oleh karena itu akan dirancang suatu sistem penjualan secara online dengan menggunakan website dengan tujuan untuk meminimalkan waktu proses penjualan dengan tujuan dapat meningkatkan volume penjualan sehingga pendapatan industri rumah tangga ini dapat meningkat dan pelanggan dapat melalukan pemesanan produk tanpa harus datang langsung ke industri rumah tangga Lia Cake.

Katakunci: website, industri, rumah, tangga, internet
\end{abstract}




\section{PENDAHULUAN}

Sistem informasi di definisikan oleh Robert A. Laitch dan K. Roscoe Bavis sebagai berikut Sistem informasi adalah suatu sistem didalam suatu organisasi yang mempertemukan kebutuhan pengolahan transaksi harian, mendukung operasi, bersifat manajerial dan kegiatan strategi dari suatu organisasi dan menyediakan pihak luar tertentu dengan laporan-laporan yang diperlukan. Definisi umum sistem informasi adalah Sebuah sistem yang terdiri atas rangkaian subsistem informasi terhadap pengolahan data untuk menghasilkan informasi yang berguna dalam pengambilan keputusan (Sukadi 2013).

Organisasi menggunakan sistem informasi untuk mengolah transaksi-transaksi, mengurangi biaya dan menghasilkan pendapatan sebagai salah satu produk atau pelayanan mereka. Bank menggunakan sistem informasi untuk mengolah cek-cek nasabah dan membuat berbagai laporan rekening koran dan transaksi yang terjadi. Perusahaan menggunakan sistem informasi untuk mempertahankan persediaan pada tingkat paling rendah agar konsisten dengan jenis barang yang tersedia (Ladjamudin 2005).

Dalam suatu sistem informasi terdapat komponen-komponen sebagai berikut :

\section{Perngkat keras (hardware), mencakup berbagai peranti fisik seperti komputer dan printer.}

2. Perangkat lunak (software) atau program, yaitu sekumpulan instruksi yang memungkinkan perangkat keras memproses data.

3. Prosedur, yaitu sekumpulan aturan yang dipakai untuk mewujudkan pemprosesan data dan pembangkitan keluaran yang di kehendaki.

4. Orang, yaitu semua pihak yang bertanggung jawab dalam pengembangan sistem informasi, pemrosesan dan penggunaan keluaran sistem informasi.

5. Basis data (database), yaitu sekumpulan tabel, hubungan dan lain-lain yang berkaitan dengan penyimpanan data.

6. Jaringan komputer dan komunikasi data, yaitu sistem penghubung yang memungkinkan sumber (resources) dipakai secara bersama tau di akses oleh sejumlah pemakai (Sukadi 2013).

Promosi / Pemasaran merupakan suatu sistem keseluruhan dari kegiatan-kegiatan bisnis yang ditujukan untuk merencanakan, menentukan harga, mempromosikan dan mendistribusikan barang atau jasa yang memuaskankebutuhan baik kepada pembeli yang ada maupun pembeli potensial (Heri, 2013).

Pada kemajuan teknologi khususnya teknologi informasi, mendorong banyak manusia untuk menciptakan inovasi-inovasi baru untuk membantu manusia dalam mendapatkan informasi dengan cepat dan mudah. Begitu halnya dengan Home Industri Lia Cake, sebuah Home Industri harus dapat membuat layanan informasi dan promosi dengan baik untuk menarik perhatian konsumen. Disamping informasi yang akurat, cepat dan mudah, informasi yang disampaikan harus dikemas dengan menarik. Home Industri Lia Cake didirikan pada bulan Sepetember 2016, awalnya Home Industri Lia Cake ini diawali dari usaha kecil-kecilan didepan rumah, modal pertama usaha ini Rp.300.000 (tiga ratus ribu rupiah), untuk bahan-bahan dan peralatan, biaya operasional untuk usaha kurang lebih 2 juta rupiah, untuk keuntungan bersihnya setiap bulan 3 juta rupiah. Home Industri Lia Cake bergerak di bidang penjualan, produksi dan pemasaran. Produk yang di hasilkan dari usaha ini bermacammacam seperti kue ulang tahun, kue pernikahan, kue bolu, kue sarang semut, risoles, cendol, fried chicken dan lain-lain. Home industri Lia Cake ini pelanggannnya tidak hanya di daerah Desa Rumbai Jaya Kec. Kempas saja namun juga sampai ke desa lain seperti pengalihan enok, sungai gantang, harapan tani sampai ke daerah indragiri hulu (rengat), namum mereka untuk membelinya harus datang ketempatnya langsung. Home industri Lia Cake ini juga menyediakan jajanan oleh-oleh khas daerah kempas, untuk harga termurah Home Industri Lia Cake ini yaitu 2 ribu sedangkan untuk yang paling mahal 100 ribu. Home Industri Lia Cake mempunyai karyawan 2 orang, Home Industri ini tidak 
mempunyai cabang dimana pun hanya ada di desa Rumbai Jaya Kec. Kempas saja. Sistem penjualan yang selama ini digunakan oleh home industriLia Cake adalah dengancara telpon atau sms dan belum secara online, untuk mempromosikannya hanya dari mulut kemulut. Sistem penjualan dengan cara ini membutuhkan waktu yang lama dalam proses penjualan, maka sistem ini dinilai kurang efektif dan efesien.

Jika hanya mengandalkan sistem penjualan dengan cara tersebut maka pendapatan pengusaha Home Industri ini tidak mengalami peningkatan yang signifikan. Selain itu perkembangan home industri ini terasa dinilai agak lambat. Oleh karena itu akan dirancang suatu sistem penjualan secara online dengan menggunakan media website atau internet dengan tujuan untuk meminimalkan waktu proses penjualan dengan tujuan dapat meningkatkan volume penjualan sehingga pendapatan home industri ini dapat meningkat.

\section{METODELOGI PENELITIAN}

Dalam melakukan penelitian banyak metode yang dilakukan untuk mengumpulkan data, metode yang di gunakan antara lain sebagai berikut :

1. Metode observasi

Observasi adalah melihat secara langsung bagaimana proses yang dilakukan oleh pengguna di tempat penelitian. Keuntungan dari observasi ini adalah bahwa sistem analis dapat lebih mengenal lingkungan secara fisik dan mengetahui kendala-kendala yang terjadi selama di tempat penelitian.

2. Wawancara

Wawancara adalah percakapan langsung antara narasumber dan pewawancara, wawancara dilakukan tanya jawab langsung antara peneliti terhadap komponen-komponen yang ada pada Toko Home Industri Lia Cake, teknik ini digunakan untuk memperoleh data dengan lengkap dengan mengajukan pertanyaan-pertanyaan kepada petugas perpustakaan.

3. Studi pustaka (Literatur)

Studi pustaka dilakukan oleh peneliti untuk menghimpun suatu informasi dari referensi atau buku, artikel, jurnal maupun situs internet mengenai sisten informasi perpustakaan serta referensi lainnya untuk menunjang pencapaian tujuan penelitian.

Selain metode penelitian diatas peneliti juga menerapakan SDLC (System Development Life
JUTI-UNISI (JurnalTenikIndustriUNISI)

Cycle / Daur hidup pengembangan sistem) berfungsi untuk menggambarkan tahapan-tahapan utama dan langkah-langkah dari setiap tahapan yang secara garis besar terbagi dalam tiga kegiatan utama yaitu :

1. Analisis

Tahapan analisis digunakan oleh analisis sistem untuk membuat keputusan.Apabila sistem saat ini mempunyai masalah atau sudah tidak berfungsi secara baik, dan hasil analisisnya digunakan sebagai dasar untuk memperbaiki sistem. Kegiatan yang dilakukan dalam analis ini adalah sebagai berikut :

1) Deteksi masalah (Problem Detection).

2) Penelitian atau investigasi awal (Initial Investigation).

3) Analisa kebutuhan sistem (Requirement Analisis).

4) Mensortir kebutuhan (Generation of System Alternatives).

5) Memilih sistem yang baik (Selection of System).

\section{Perancangan / Desain}

Tahapan perancangan (design) memiliki tujuan untuk mendesign sistem baru yang dapat menyelesaikan masalah-masalah yang dihadapi perusahaan yang diperoleh dari pemilihan alternative sistem yang terbaik, kegiatan yang dilakukan dalam tahap perancangan ini meliputi perancangan output, input dan file.

\section{Implementation}

Tahap implementasi memeiliki beberapa tujuan, yaitu utuk melakukan kegiatan spesifikasi rancangan logical kedalam kegiatan yang sebenarnya dari sistem informasi yang akan dibangunnya atau dikembangkannya, lalu mengimplementasikan sistem yang baru tersebut kedalam salah satu bahasa pemograman yang paling sesuai. Pada tahap ini juga harus dijamin bahwa sistem yang baru dapat berjalan optimal. Kegiatan yang dilakukan dalam tahap implementasi ini adalah pembuatan program dan test data, pelatihan dan pergantian sistem (Albahra, 2005).

\section{HASIL DAN PEMBAHASAN}

Sebelum dilakukannya perancangan sebuah sistem, diperlukan adanya suatu gambaran yang memuat keterangan atau informasi yang berhubungan dengan sistem yang ada sekarang atau sistem yang sedang berjalan pada ecommerce Lia Cake. Hal ini bertujuan agar mempermudah 
dalam menganalisa dan merancang sistem yang baru.

3.1. Bagan Alur (flowchart)

Pada bagian Metode Penelitian terdapat Bagan Alur (Flowchat) Metode Penelitian, seperti yang tertera pada Gambar 1

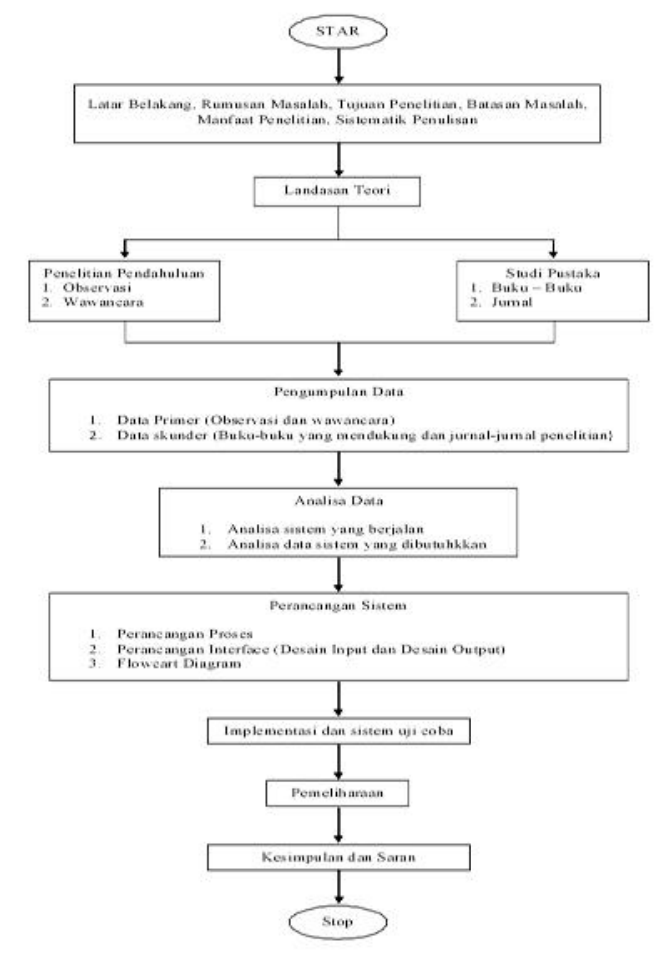

Gambar 1. Bagan Alur (Flowchart)

\subsection{Analisis Kebutuhan Sistem}

Analisa kebutuhan yang di perlukan adalah kebutuhan perangkat lunak (software), perangkat keras (hardware) dan manusia.

1. Perangkat keras (Hardware), kebutuhan perangkat keras (Hardware) yang digunakan dalam membangun sistem ini sebagai berikut (1) Processor Intel (R) $1 \mathrm{GHz}, 2$ RAM $1 \mathrm{~Gb}$, (3) Harddisk $32 \mathrm{~Gb}$, (4) Printer Brother, (5) Modem Internet.

2. Kebutuhan perangkat lunak (Software) yang digunakan dalam membangun sistem ini sebagai berikut (1) Editor Tool : Macromedia Dreamweaver CS 8, (2) Server Xamppwin32-1.7.3, (3) Database MySQL, (4) Web Browser Firefox / Google Chrome.

3. Pengguna Sistem, manusia sebagai pengendali sistem yang akan dibuat.

\subsection{Rancangan Sistem}

Rancangan sistem berguna untuk memberikan gambaran kepada Pengguna tentang sistem yang diterapkan, guna mempermudah pemakaian dan memberi pemahaman atau pengertian tentang website e-commerce Lia Cake yang akan diterapkan. Perancangan Sistem pada Penelitian ini menggunakan metode unified modelling language (UML) yang terdiri dari use case diagram, activity diagram, squence diagram dan class diagram.

\subsubsection{Use Case Diagram}

Pada rancangan usulan use case diagram ini menggambarkan aktivitas-aktivitas yang sebanarnnya terjadi pada rancangan sistem yang dibuat.

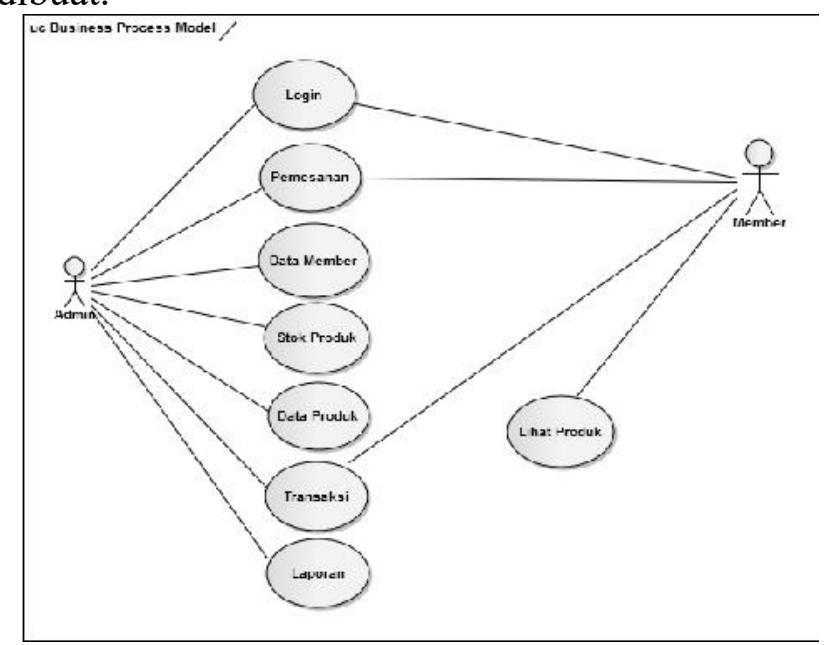

Sumber : Data diolah, 2019

Gambar 2. Use Case Diagram e-Commerce Lia Cake

Gambar 2 Use Case Diagram e-Commerce Lia Cake menggambarkan bagaimana sistem penjualan secara online pada Home Industri Lia Cake, yaitu terdiri dari Admin yang bertugas melayani transaksi, membuat laporan penjualan barang, melakukan input barang, melakukan update barang, kemudian pembeli yang melakukan transaksi pembelian serta pemilik toko yang menerima laporan penjualan perbulan.

\subsubsection{Activity Diagram}

Pada rancangan usulan activity diagram ini menggambarkan aktivitas-aktivitas yang sebanarnnya terjadi pada rancangan sistem yang dibuat.

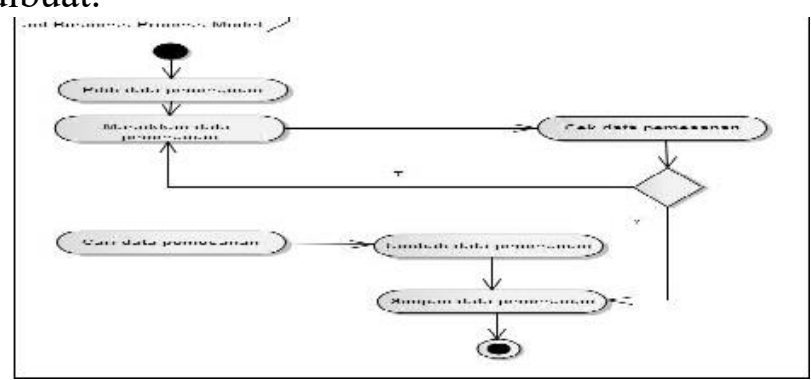


Sumber : Data diolah, 2019

Gambar 3. Activity Diagram

Aktivitas Pemesanan

Pada Gambar 3 rancangan activity diagram, admin memasukkan data pemesanan. Setelah itu melakukan pemesanan, cek data pemesanan, cari data pemesanan, ubah data pemesanan dan sistem memproses data pemesanan yang telah dimasukkan, jika data terisi dengan benar maka sistem akan menyimpan secara otomatis, jika tidak terisi dengan benar maka sistem akan mengembalikan ke menu masukkan data pemesanan.

\subsubsection{Squence Diagram}

Pada rancangan usulan sequence diagram ini menggambarkan aktivitas-aktivitas yang sebanarnnya terjadi pada rancangan sistem yang dibuat.

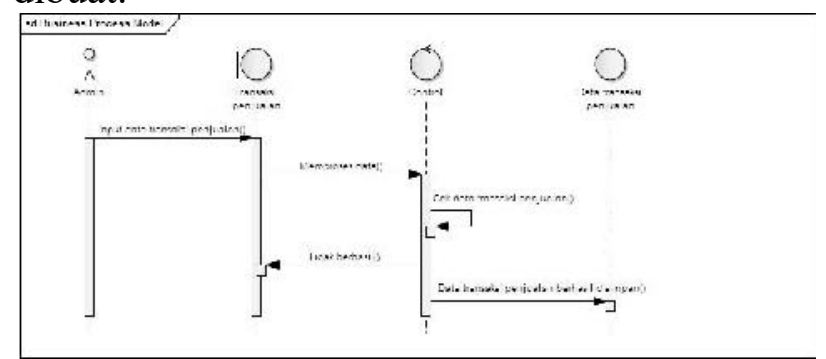

Sumber : Data diolah, 2018

Gambar 4. Squence Diagram Aktivitas Penjualan

Pada Gambar 4 rancangan sequence diagram aktivitas Admin masuk ke menu data transaksi penjualan, setelah itu melihat data transaksi penjualan, lalu admin memeriksa data transaksi penjualan. Setelah itu sistem mengecek data transaksi penjualan jika benar sistem akan menampilkan dan menyimpan data transaksipenjualan kedalam database.

\subsubsection{Class Diagram.}

Class diagram dibawah ini menggambarkan hubungan dari setiap kelas-kelas atau tabel-tabel dalam database. Pada Gambar dibawah terlihat bahwa website Penjualan online pada website ecommerce Lia Cake memiliki empat buah tabel, yaitu yang terdiri dari produk/barang, pemesanan,transaksi, pembeli, dan pemesanan.

Berikut ini gambar adalah Class diagram pada website sebagai administrator website eCommerce Lia Cake:

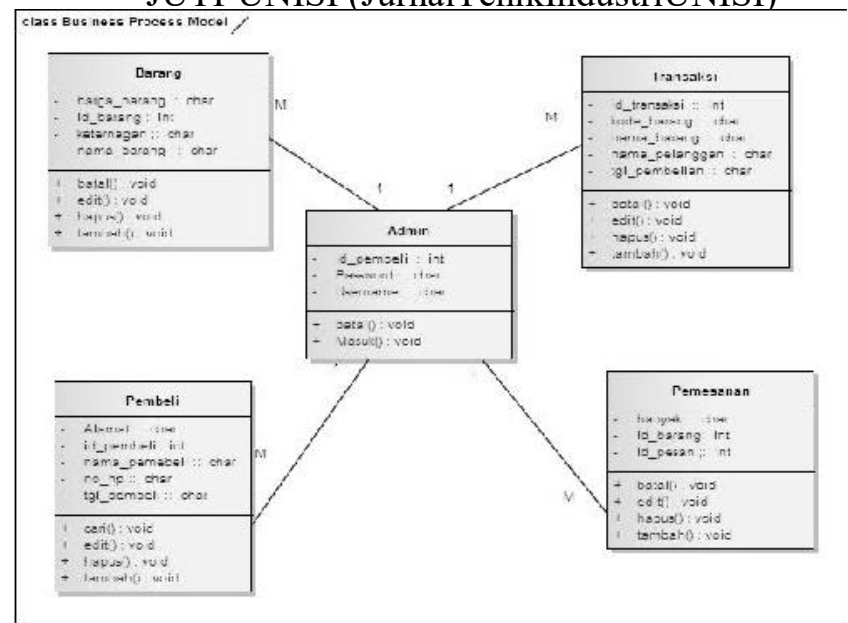

Sumber : Data diolah, 2019

Gambar 5. Class Diagram

Aktivitas UED-SP

\subsection{Perancangan Antar Muka Sistem}

Berikut ini merupakan rancangan interface/antarmuka yang dibuat, adapun macammacam desain dijalasakan pada gambar-gambar dibawah ini

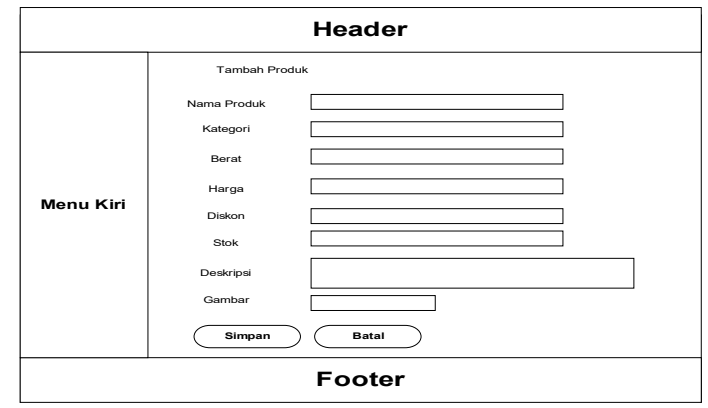

Sumber : Data diolah, 2019

Gambar 6. Perancangan Input Produk

Gambar 6 menggambarkan rancangan input produk website e-Commerce Lia Cake dimana terdapat menu simpan dan batal.

Sumber : Data diolah, 2019

Gambar 7. Perancangan Input Pemesanan

Gambar 7 menggambarkan rancangan input pemesanan produk pada website e-Commerce Lia Cake, dimana member harus memilih produk yang hendak dibeli kemudian mengisi form pemesanan. 


\begin{tabular}{|c|c|c|c|}
\hline \multicolumn{4}{|c|}{ Header } \\
\hline Kategori & & & Bank Pembayaran \\
\hline & Nama & $\square$ & \\
\hline & E-mai & $\square$ & \\
\hline & Subjek & $\square$ & \\
\hline & Pesan & & \\
\hline & Kirim & & \\
\hline
\end{tabular}

Sumber : Data diolah, 2019

Gambar 8. Perancangan Data Master

Gambar 8 menggambarkan rancangan input data member produk pada website e-Commerce Lia Cake, dimana member yang sudah login harus memilih produk yang hendak dibeli kemudian mengisi form data member.

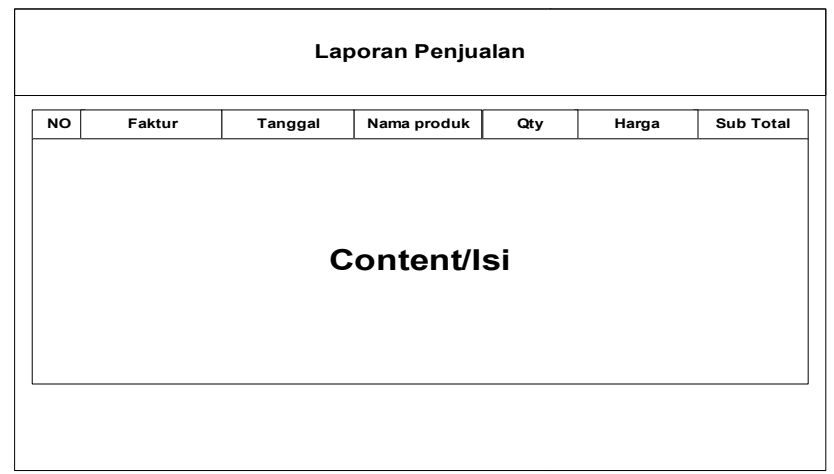

Sumber : Data diolah, 2019

Gambar 9. Perancangan Laporan

Gambar 9 menggambarkan output laporan pada e-Commerce Lia Cake, terdapat laporan rekap penjualan serta hasil total penjualan.

\subsection{Implementasi Sistem Informasi}

Implementasi merupakan mempresentasikan hasil desain kedalam program, yang mana dalam tahap ini peneliti merancang sistem informasi menggunakan bahasa pemrograman Php dan untuk penyimpanan data dalam bentuk database MySQL. Implementasi sistem ini bertujuan untuk membangan website e-Commerce Lia Cake.

\subsubsection{Implementasi Program}

Implementasi / penerapan program pada website e-Commerce Lia Cake berdasarkan hasil perancangan antarmuka dengan menggunakan software pendukung dan database support.

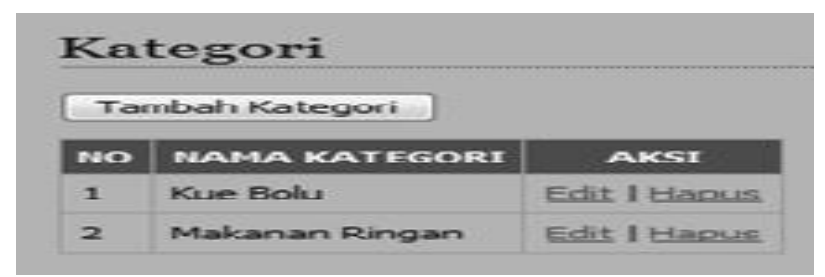

Sumber : Data diolah, 2019

Gambar 10. Input Kategori Makanan

\section{JUTI-UNISI (JurnalTenikIndustriUNISI)}

e-Commerce Lia Cake

Gambar 10 adalah form untuk melakukan input kategori makanan yang dijual pada eCommerce Lia Cake, kategori makanan yang dijual pada e-Commerce Lia Cake ada dua jenis yaitu makanan ringan dan kue bolu.

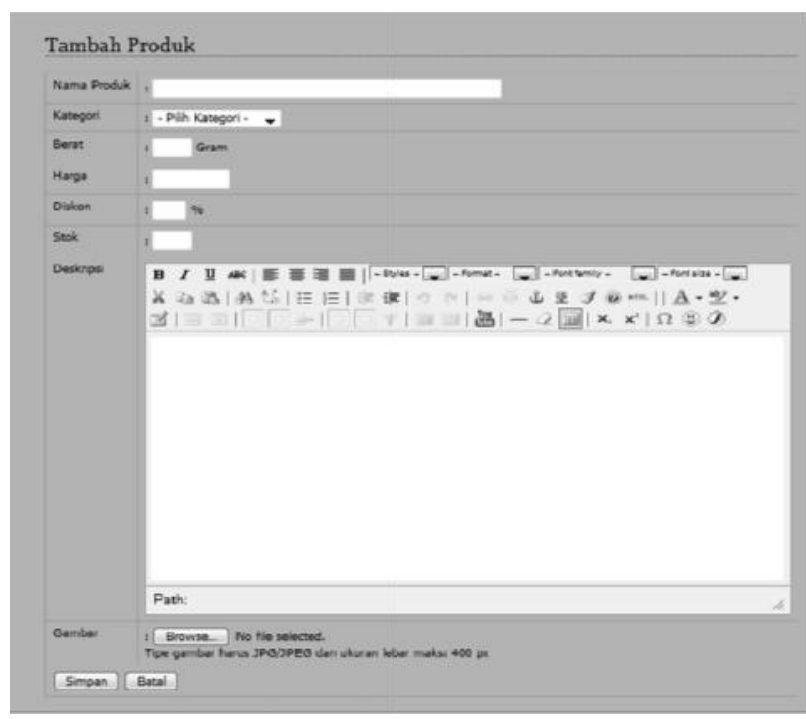

Sumber : Data diolah, 2019

Gambar 11. Input Produk Makanan e-Commerce Lia Cake

Gambar 11 adalah menu untuk melakukan input produk makanan, data-data yang di input antara lain adalah nama produk, kategori makanan, berat, harga, diskon, stok, deskripsi dan gambar produk.

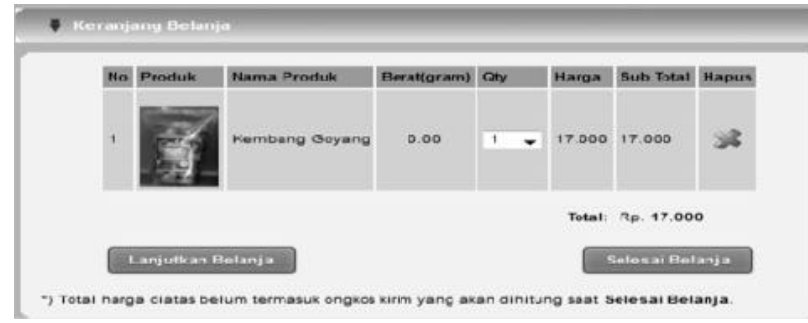

Sumber : Data diolah, 2019

Gambar 12. Halaman Input Pemesanan e-Commerce Lia Cake

Gambar 12 adalah menu untuk melakukan input produk belanjaan makanan oleh pembeli, dimana seorang pembeli harus melakukan input jumlah item yang akan dibeli. 


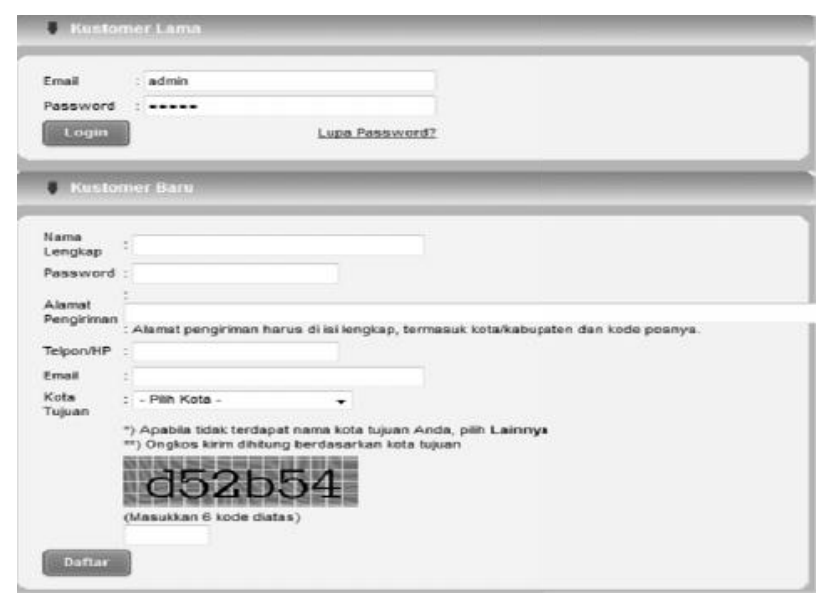

Sumber : Data diolah, 2019

Gambar 13. Input Data Pembeli e-Commerce Lia Cake

Gambar 13 adalah menu untuk melakukan input data pengiriman oleh pembeli dengan mengisi form gambar diatas serta memasukkan kode yg telah tertera pada form tersebut.

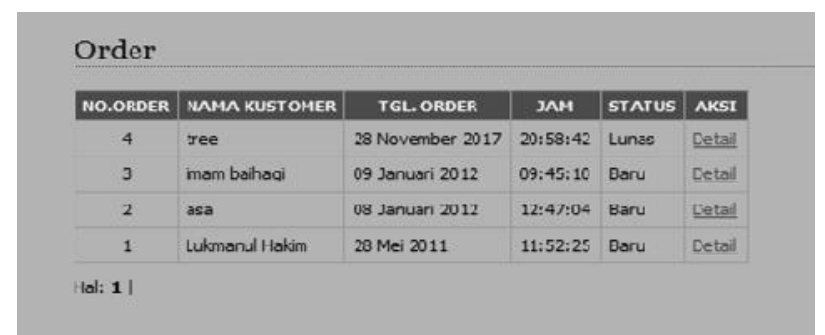

Sumber : Data diolah, 2019

Gambar 14. Halaman Orderan Masuk e-Commerce Lia Cake

Gambar 14 adalah tampilan data orderan masuk yang dilakukan oleh pembeli, data yang ditampilkan antara lain adalah no order, nama kustomer, tanggal order, jam dan status orderan, dan aksi.

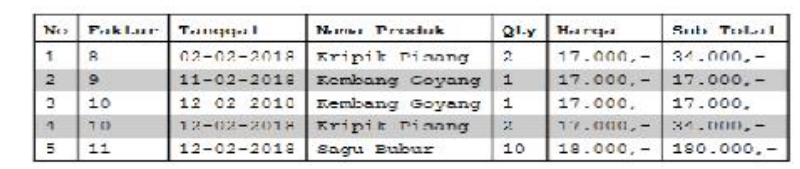

rotal kosolurulan : kp. 202.000,

Jumlah yang terjusi : 5 unit

Sumber : Data diolah, 2019

Gambar 15. Halaman Cetak Laporan e-Commerce Lia Cake

Gambar 15 adalah tampilan laporan penjualan bulanan, dimana terdapat keterangan no, faktur, tanggal pembelian, qty, harga dan sub total.

\subsection{Pengujian Sistem}

Setelah sistem selesai dibuat, selanjutnya sistem akan diuji kelayakannya. Pada tahap ini
JUTI-UNISI (JurnalTenikIndustriUNISI) pengujian dilakukan dengan black box. Pengujian black box dilakukan untuk mengetahui segala kemungkinan yang dapat menimbulkan kesalahan sesuai dengan spesifikasi perangkat lunak yang telah ditentukan, sebelum perangkat lunak tersebut diterapkan.

\subsubsection{Blackbox Testing}

Black box testing adalah pengujian yang dilakukan hanya mengamati hasil eksekusi melalui data uji dan memeriksa fungsional dari perangkat lunak. Pengujian black box mengevaluasi hanya dari tampilan luarnya (interfacenya), fungsionalnya. Tanpa mengetahui apa sesungguhnya yang terjadi dalam proses detailnya hanya mengetahui input dan output.

Tabel 1. Black Box Testing

\begin{tabular}{|c|c|c|c|}
\hline $\begin{array}{l}\text { Input/ } \\
\text { Event }\end{array}$ & Proses & Output & $\begin{array}{c}\text { Hasil } \\
\text { Pengujian }\end{array}$ \\
\hline $\begin{array}{l}\text { Penekanan } \\
\text { tombol } \\
\text { simpan }\end{array}$ & $\begin{array}{l}\text { Melakukan } \\
\text { proses atau } \\
\text { penyimpanan } \\
\text { sesuai } \\
\text { dengan data } \\
\text { produk }\end{array}$ & $\begin{array}{l}\text { Data } \\
\text { produk } \\
\text { baru } \\
\text { disimpan } \\
\text { pada } \\
\text { tabel } \\
\text { barang }\end{array}$ & Sesuai \\
\hline $\begin{array}{l}\text { Penekanan } \\
\text { menu } \\
\text { laporan }\end{array}$ & $\begin{array}{l}\text { Layar } \\
\text { laporan data } \\
\text { produk dan } \\
\text { penjualan } \\
\text { terbuka }\end{array}$ & $\begin{array}{l}\text { Data } \\
\text { produk } \\
\text { dan } \\
\text { penjualan }\end{array}$ & Selesai \\
\hline $\begin{array}{l}\text { Penekanan } \\
\text { tombol } \\
\text { login }\end{array}$ & $\begin{array}{l}\text { Melakukan } \\
\text { proses login } \\
\text { pengguna } \\
\text { agar dapat } \\
\text { masuk ke } \\
\text { halaman } \\
\text { utama }\end{array}$ & $\begin{array}{l}\text { Pengguna } \\
\text { masuk } \\
\text { kedalam } \\
\text { sistem }\end{array}$ & Sesuai \\
\hline $\begin{array}{l}\text { Penekanan } \\
\text { LoginAdmin }\end{array}$ & $\begin{array}{l}\text { Melakukan } \\
\text { proses login } \\
\text { admin agar } \\
\text { dapat masuk } \\
\text { kehalaman } \\
\text { utama admin }\end{array}$ & $\begin{array}{l}\text { Admin } \\
\text { masuk } \\
\text { kedalam } \\
\text { sistem }\end{array}$ & Sesuai \\
\hline
\end{tabular}

Sumber : Data diolah, 2019 


\subsubsection{Whitebox Testing}

Tabel 2. White Box Testing

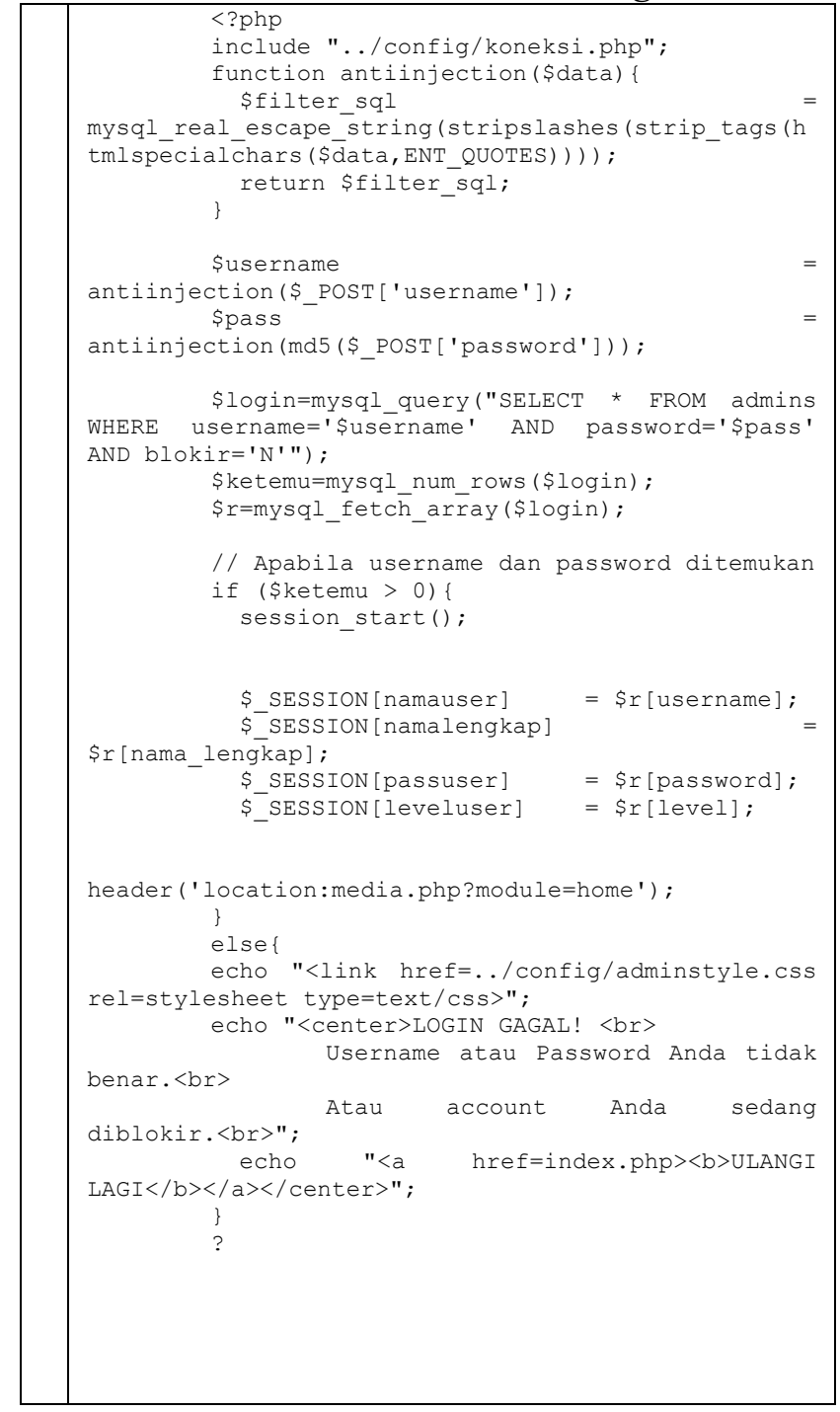

Sumber : Data diolah, 2019

Berdasarkan pseudodecode diatas maka diagram alirannya sebagai berikut :

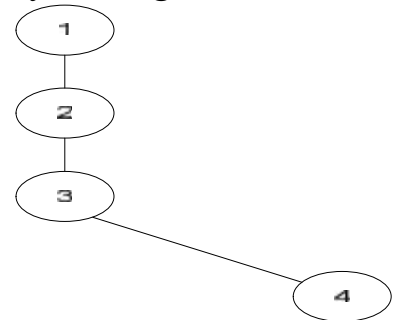

Gambar 16. Flow Graph Notasi Login e-Commerce Lia Cake

Dari diagram alir diatas, dapat dihitung cyclomatic complexity, yaitu :

1) Flograf mempunyai 1 region

2) $\mathrm{V}(\mathrm{G})=3$ edge -4 node $+2=4$

3) $\mathrm{V}(\mathrm{G})=1$ predicade node $+1=2$
Dari hasil perhitungan cyclomatic complexity terdapat 1 independen path, yaitu : Path $1=$ $1,2,3,4$

\section{KESIMPULAN}

Perancangan website e-Commerce Lia Cake ini merupakan salah satu cara untuk memudahkan untuk menyebarkan informasi ke masyarakat luas. Adapun kesimpulan yang dapat diambil dari pembahasan sebelumnya, yaitu sebagai berikut:

1. Aplikasi yang di bangun, dapat membantu pelanggan mengetahui informasi mengenai produk-produk yang ada di home industri Lia Cake.

2. Aplikasi yang telah dibangun dapat memfasilitasi layanan pemasaran dan order bagi home idustri Lia Cake sehingga meningkatkan omset penjualan.

3. Aplikasi yang telah dibangun, dapat membantu pelanggan agar dapat berkomunikasi dengan petugas toko melalui jaringan internet.

4. Dari Aplikasi yang telah dibangun, pemilik toko dapat melihat laporan transaksi penjualan setiap bulannya melalui aplikasi ini.

\section{DAFTAR PUSTAKA}

Ahmad Susanto, N. M. (2016). Rancang Bangun Sistem Informasi Penjualan Batik BerbasisECommerce. Evolusi, 5(1), 16.Retrieved from http://lppm3.bsi.ac.id/jurnal/index.php/evo/ar ticle/view/234

Harun Al-Rosyid, Bambang Eka Purnama, I. U. W. (2010). Sistem Informasi Penjualan Buku Berbasis Website Pada Toko Buku Standard Book Seller Pacitan. Indonesian Journal on Networking Security, 7(2), 1-6.

Luthfi, H. W., \& Riasti, B. K. (2013). Sistem Informasi Perawatan Dan Inventaris Laboratorium Pada Smk Negeri 1 Rembang Berbasis Web. Indonesian Jurnal on Computer Science - Speed (IJCSS), 10(1), 83-91.

Muntiani, \& Irianto, T. (2012). Sistem Informasi Pembuatan Surat Pemesanan Obat Berbasis sms gateway pada PT. Sehat Bersama Sejahtera. Jurnal Speed 13 FTI UNSA, 9(2), 157-163. 